\title{
Perception of confidence among dental interns when performing removable prosthodontic treatment
}

\author{
Maskey B ${ }^{1}$, Shrestha $\mathrm{K}^{2}$, Pathak B ${ }^{3}$ \\ ${ }^{1,3}$ Assistant Professor, Department of Prosthodontics and Maxillofacial Prosthetics, People's Dental College and \\ Hospital, Kathmandu, Nepal \\ ${ }^{2}$ Associate Professor, Department of Prosthodontics and Maxillofacial Prosthetics, People's Dental College and Hospital, \\ Kathmandu, Nepal
}

\begin{abstract}
Introduction: Removable prosthodontics constitutes the majority of the prosthodontic curriculum at an undergraduate level and it is expected that the students will be able to perform these procedures independently. However, in recent years, it has been observed that the majority of the removable prosthodontic treatment have been referred to consultants or at times even delegated to the technicians. One of the major reasons behind this trend may be the result of an individual graduate internal perception of their ability or lack of confidence in their ability to perform these procedures.

Materials and Methods: A cross-sectional study was conducted among dental interns in People's Dental College and Hospital, affiliated to Tribhuvan University, Kathmandu, Nepal after the ethical approval from PDCH-IRC. A self-designed validated questionnaire related to experience of individual intern and level of confidence pertaining to clinical procedures related to removable prosthesis fabrication was distributed by the authors to the interns. The data were analyzed using SPSS software (version 21); descriptive statistics and Fisher's exact test was applied.

Results: Overall most of the interns $(77.8 \% ; n=28)$ were confident in removable prosthodontics and they were equally confident while performing both complete and partial denture prostheses. Male interns were significantly more confident $(p<0.5)$ in performing complete denture prostheses while the clinical experience did not have significant effect on the confidence level. The interns were confident in performing most of the procedures related to complete and partial denture prostheses (median=3). Conclusions: The interns at People's Dental College and Hospital were confident in removable prosthodontics. The few procedures where our interns lacked have been identified and efforts will be made to overcome these shortcomings.
\end{abstract}

Key words: Confidence; Removable prosthodontics; Undergraduate.

\section{Introduction}

$\mathrm{R}$ emovable prosthodontics (RP) is "the branch of prosthodontics concerned with the replacement of teeth and contiguous structures for edentulous or partially edentulous

\section{Conflict of Interest: No}

\section{*Corresponding Author}

Dr. Brijesh Maskey, Assistant Professor

Department of Prosthodontics and Maxillofacial

Prosthetics, People's Dental College and Hospital,

Kathmandu, Nepal

E-mail: bridgesmaskey@yahoo.com patients by artificial substitutes that are readily removable from the mouth by the patient". ${ }^{1}$ These include various forms of removable denture prostheses, among which conventional complete dentures and acrylic removable partial dentures are by far, the most common ones used worldwide. $^{2}$ They are very popular owing to their low cost, noninvasive nature and ease of fabrication.

Irrespective of the universities in Nepal, RP constitutes major portion of the prosthodontic curriculum in undergraduate program. To put things into perspective, the entire preclinical 
years and about two-third of the clinical years are dedicated to learning and performing procedures related to RP. Besides, large part of the assessment in prosthodontics is related to performing procedures related to RP. So, upon graduation it is expected that the students have the necessary knowledge and skill to provide these prostheses when indicated. However, often times, it has been observed that some dentists lack confidence in providing these prostheses upon graduation.,

Confidence is the self-perceived ability of an individual to perform procedures successfully or at least properly and independently. ${ }^{5}$ It is an integral part of the learning process and practice. ${ }^{6}$ Hence, as an educator it is imperative to understand the level of confidence among the undergraduates before they venture out to work independently. Furthermore, there is a general consensus that procedural confidence can be improved with repeated exercises. ${ }^{4,7-11}$ Considering these aspects, this study aims to evaluate the level of confidence among the interns while performing procedures concerning removable complete and acrylic partial dentures and whether it improved with experience as claimed by general consensus. Furthermore, the study will also explore the confidence level of students with respect to each procedure or steps for fabrication of removable prosthesis.

\section{Materials and Methods}

A cross-sectional study was conducted at People's Dental College and Hospital from $27^{\text {th }}$ of September, 2020 to $31^{\text {st }}$ November, 2020 for a period of 2 months. Ethical approval was taken from the People's Dental College and Hospital Institutional Research Committee (PDCH-IRC Ref Nos 01. CH Nos 04.2077/2078) prior to the commencement of the study. The target sample population involved all the 55 dental interns as identified through the records of the hospital administration at the time of survey.
A semi-structured, self-administered questionnaire was developed to evaluate the level of confidence among dental interns when performing removable prosthodontic treatment. The questionnaire was face-validated by the experts from the field and few amendments were made as suggested. The questionnaire was also pretested among 5 of the interns and they were not included for the final assessment. Furthermore, the questionnaire demonstrated consistent levels of reliability and validity with the original Cronbach's alpha coefficient of less than 0.8 .

The questionnaire consisted of two parts: The first part was based on demographic variables such as age and gender. The second part consisted of five questions inquiring about three aspects. The first inquired about the number of removable denture prostheses cases done, the second and third allowed the students to self-rate their clinical confidence for the same in general and with respect to each step of fabrication respectively. The respondents were asked to rate their level of confidence on a scale of 1-4, where: 1="not confident", 2="low confident", $3=$ "confident" and $4=$ "very confident".

The digital version of the questionnaire was created in google form and the link was emailed individually to all the dental interns on $27^{\text {th }}$ of September, 2020. There were no exclusion criteria except for the ones who refused participation. A cover sheet explaining the objectives of the study and informing that the participation was optional, voluntary and anonymous was provided to all the interns. Consent was implied by the participants choosing to take part in the study.

A follow up email was sent on second and third week i.e. $4^{\text {th }}$ and $11^{\text {th }}$ October, 2020 respectively to all the participants as a reminder for participation. To limit the responses to one per person, the respondents were required to sign in with their individual google account which 
would automatically avoid any duplication. A thank you note was also sent to the ones who had taken time to complete the questionnaire.

The data were analysed using Statistical Package for Social Sciences (SPSS Version 21, IBM Corp, New York, USA). Descriptive statistics was applied for calculating percentage, frequency count, median and inter quartile range (IQR). Fisher's exact test was applied for inferential statistics and statistical significance was set at a level of 0.05 .

\section{Results}

In this study, $100 \%$ response rate was obtained, corresponding to 50 valid questionnaires. Of the respondents, $11(22 \%)$ and 39 (78\%) were male and female respectively. The mean age of the interns was $24.7 \pm 1.3$ years, ranging from 23 to 30 years. On an average $2.3 \pm 1.3$ removable partial denture prostheses (RPDP) and $2.1 \pm 0.4$ removable complete denture prostheses (RCDP) were completed by the interns. Majority of the interns completed two or less cases of both RPDP and RCDP. (Table 1)

\section{Level of confidence of the interns}

For the purpose of evaluating the overall level of confidence and confidence level based on the type of prosthesis, the four ratings were grouped into two categories i.e. lack of confidence (not confident and low confident) and confident (confident and very confident). Overall, majority of the interns were confident while performing RPDP ( $n=36)$ and RCDP $(n=35)$. Majority of the interns $(77.8 \% ; n=28)$ were confident in both RPDP and RCDP but they were still 7 interns who lacked confidence in both. Among the interns who were confident in RPDP, $22.2 \%(n=8)$ lacked confidence in RCDP. Likewise, there were also 7 interns (50\%) who lacked confidence in RPDP but were confident in RCDP. The result revealed that the interns were equally confident in either of the procedure with no statistically significant difference (0.059). (Table 2)
Discrepancies between gender, age and experience were assessed based on the overall self-confidence of interns regarding RPDP and RCDP (questions 2 and 3, respectively).

\section{Level of confidence based on gender}

Although $81.8 \%$ of male interns were either "confident" or "very confident" while carrying out RPDP opposed to $69.3 \%$ of female interns, it was not statistically significant. However, statistically significant $(p<.05)$ sex difference was found for RCDP related procedures, with a higher percentage of male interns $(90.6 \%)$ feeling "confident" or "very confident" than female interns $(64.1 \%)$. (Table 3$)$

\section{Level of confidence based on clinical experience}

Majority of the interns who had completed more than two cases of RPDP (90\%) and RPCD $(85.7 \%)$ were confident or very confident. However, there was no statistically significant difference in the confidence level when compared with the ones who had undertaken just two or less than two of these prostheses. (Table 4)

\section{Level of confidence while carrying out specific procedures in removable partial and complete denture prosthesis treatment}

The analysis of the students' self-confidence levels was based on the median value so as to dilute the effect of potential outliers. The interns were confident in most of the procedures in RPDP except during "recording the jaw relationships/ bite registration" (median=2) and "repairing denture" (median=2). There was $62 \%$ and $54 \%$ of the interns who lacked confidence in the carrying out jaw relation and repairing RPDP respectively. (Table 5) With respect to RCDP, the interns lacked confidence (median=2) in recording the jaw relationships, reline and rebasing. (Table 6) 
Table 1: Background Characteristics of the interns

\begin{tabular}{|c|c|c|}
\hline Characteristics & $\mathbf{n}$ & $\%$ \\
\hline \multicolumn{3}{|l|}{ Gender } \\
\hline Male & 11 & 22 \\
\hline Female & 39 & 78 \\
\hline \multicolumn{3}{|l|}{ Age } \\
\hline$<25$ years & 25 & 50 \\
\hline$\geq 25$ years & 25 & 50 \\
\hline \multicolumn{3}{|c|}{ Removable Dental Procedure completed } \\
\hline Mean \pm SD (Partial) & \multicolumn{2}{|c|}{$2.3 \pm 1.3$} \\
\hline Mean \pm SD (Complete) & \multicolumn{2}{|c|}{$2.1 \pm 0.4$} \\
\hline \multicolumn{3}{|c|}{ Removable partial Dental Procedure completed } \\
\hline Up to 2 & 30 & 60 \\
\hline More than 2 & 20 & 40 \\
\hline \multicolumn{3}{|c|}{ Removable complete Dental Procedure completed } \\
\hline Up to 2 & 43 & 86 \\
\hline More than 2 & 7 & 14 \\
\hline Mean Age & \multicolumn{2}{|c|}{$24.7 \pm 1.3$} \\
\hline Age Range & \multicolumn{2}{|c|}{$23-30$} \\
\hline
\end{tabular}

Table 2: Level of confidence based on the type of prosthesis

\begin{tabular}{|c|c|c|c|c|}
\hline & & \multicolumn{2}{|c|}{ RCDP confidence } & \\
\hline \multirow{2}{*}{$\begin{array}{c}\text { RPDP } \\
\text { confidence }\end{array}$} & Lack of confidence & Lack of confidence & Confident & p-value \\
\cline { 2 - 5 } & Confident & $7(50)$ & $7(50)$ & \multirow{2}{*}{.059} \\
\hline
\end{tabular}

Fisher's Exact Test

Table 3: Level of confidence based on gender while carrying out RPDP and RCDP

\begin{tabular}{|c|c|c|c|c|c|c|}
\hline Prosthesis & Gender & Not confident & Low confident & Confident & Very confident & p-value \\
\hline \multirow{2}{*}{ RPDP } & Male & $0(0.0)$ & $2(18.2)$ & $9(81.8)$ & $0(0.0)$ & \multirow{2}{*}{0.820} \\
\cline { 2 - 6 } & Female & $1(2.6)$ & $11(28.2)$ & $26(66.7)$ & $1(2.6)$ & \\
\multirow{2}{*}{ RCDP } & Male & $0(0.0)$ & $1(9.1)$ & $6(54.5)$ & $4(36.4)$ & \multirow{2}{*}{0.001} \\
\cline { 2 - 7 } & Female & $0(0.0)$ & $14(35.9)$ & $25(64.1)$ & $0(0.0)$ & \\
\hline
\end{tabular}

Fisher's Exact Test

Table 4: Level of confidence based on clinical experience while carrying out RPDP and RCDP

\begin{tabular}{|c|c|c|c|c|c|c|}
\hline \multirow{2}{*}{ Prosthesis } & Gender & Not confident & $\begin{array}{c}\text { Low } \\
\text { confident }\end{array}$ & Confident & $\begin{array}{c}\text { Very } \\
\text { confident }\end{array}$ & p-value \\
\hline \multirow{2}{*}{ RPDP } & Up to 2 & $1(3.3)$ & $11(36.7)$ & $18(60.0)$ & $0(0.0)$ & \multirow{2}{*}{0.055} \\
\cline { 2 - 7 } & More than 2 & $0(0.0)$ & $2(10.0)$ & $17(85.0)$ & $1(5.0)$ & \\
\hline \multirow{2}{*}{ RCDP } & Up to 2 & $0(0.0)$ & $14(32.6)$ & $25(58.1)$ & $4(9.3)$ & \multirow{2}{*}{0.546} \\
\cline { 2 - 7 } & More than 2 & $0(0.0)$ & $1(14.3)$ & $6(85.7)$ & $0(0.0)$ & \multirow{2}{*}{} \\
\hline
\end{tabular}

Fisher's Exact Test

Table 5: Level of confidence while carrying out specific procedures in removable partial denture

\begin{tabular}{|l|c|c|c|c|c|}
\hline \multirow{3}{*}{ Procedure } & \multicolumn{4}{|c|}{ Number of interns (n) and percent (\%) } & Median \\
\cline { 2 - 6 } & $\begin{array}{c}\text { Not } \\
\text { confident }\end{array}$ & $\begin{array}{c}\text { Low } \\
\text { confident }\end{array}$ & Confident & $\begin{array}{c}\text { Very } \\
\text { confident }\end{array}$ & (IQR) \\
\hline History taking & $0(0.0)$ & $7(14.0)$ & $36(72.0)$ & $7(14.0)$ & $3(3-3)$ \\
\hline
\end{tabular}




\begin{tabular}{|l|c|c|c|c|c|}
\hline Intraoral/ extra oral examination & $0(0.0)$ & $9(18.0)$ & $36(72.0)$ & $5(10.0)$ & $3(3-3)$ \\
\hline Selection of stock tray & $0(0.0)$ & $5(10.0)$ & $38(76.0)$ & $7(14.0)$ & $3(3-3)$ \\
\hline Recording impressions & $1(2.0)$ & $9(18.0)$ & $35(70.0)$ & $5(10.0)$ & $3(3-3)$ \\
\hline $\begin{array}{l}\text { Recording the jaw relationships/ Bite } \\
\text { registration }\end{array}$ & $0(0.0)$ & $31(62.0)$ & $19(38.0)$ & $0(0.0)$ & $2(2-3)$ \\
\hline Selecting the shade and mould & $0(0.0)$ & $17(34.0)$ & $33(66.0)$ & $0(0.0)$ & $3(2-3)$ \\
\hline $\begin{array}{l}\text { Carrying out the try-in stage } \\
\text { Carrying out the insertion/delivery stage }\end{array}$ & $0(0.0)$ & $11(22.0)$ & $38(76.0)$ & $1(2.0)$ & $3(3-3)$ \\
\hline $\begin{array}{l}\text { Carrying out follow up } \\
\text { Repairing denture: replacing dislodged } \\
\text { tooth or repairing fractured existing } \\
\text { denture }\end{array}$ & $0(0.0)$ & $6(12.0)$ & $40(80.0)$ & $4(8.0)$ & $3(3-3)$ \\
\hline
\end{tabular}

Table 6: Level of confidence while carrying out specific procedures in removable partial denture

\begin{tabular}{|l|c|c|c|c|c|}
\hline \multirow{2}{*}{ Procedure } & \multicolumn{2}{c}{ Number of interns (n) and percent (\%) } & Median \\
\cline { 2 - 5 } & $\begin{array}{c}\text { Not } \\
\text { confident }\end{array}$ & $\begin{array}{c}\text { Low } \\
\text { confident }\end{array}$ & Confident & $\begin{array}{c}\text { Very } \\
\text { confident }\end{array}$ & (IQR) \\
\hline History taking & $0(0.0)$ & $10(20.0)$ & $34(68.0)$ & $6(12.0)$ & $3(3-3)$ \\
\hline Intraoral/ extraoral examination & $0(0.0)$ & $11(22.0)$ & $32(64.0)$ & $7(14.0)$ & $3(3-3)$ \\
\hline Selection of stock tray & $0(0.0)$ & $6(12.0)$ & $40(80.0)$ & $4(8.0)$ & $3(3-3)$ \\
\hline Recording primary impressions & $0(0.0)$ & $11(22.0)$ & $35(70.0)$ & $4(8.0)$ & $3(3-3)$ \\
\hline $\begin{array}{l}\text { Recording border molding and } \\
\text { secondary impressions }\end{array}$ & $0(0.0)$ & $6(12.0)$ & $38(76.0)$ & $6(12.0)$ & $3(3-3)$ \\
\hline Recording the jaw relationships & $0(0.0)$ & $29(58.0)$ & $21(42.0)$ & $0(0.0)$ & $2(2-3)$ \\
\hline Selecting the shade and mould & $0(0.0)$ & $14(28.0)$ & $33(66.0)$ & $3(6.0)$ & $3(2-3)$ \\
\hline Carrying out the try-in stage & $0(0.0)$ & $11(22.0)$ & $36(72.0)$ & $3(6.0)$ & $3(3-3)$ \\
\hline $\begin{array}{l}\text { Carrying out the insertion/delivery } \\
\text { stage }\end{array}$ & $0(0.0)$ & $9(18.0)$ & $38(76.0)$ & $3(6.0)$ & $3(3-3)$ \\
\hline Carrying out follow up & $0(0.0)$ & $3(6.0)$ & $43(86.0)$ & $4(8.0)$ & $3(3-3)$ \\
\hline $\begin{array}{l}\text { Repairing denture: replacing } \\
\text { dislodged tooth or repairing }\end{array}$ & $1(2.0)$ & $21(42.0)$ & $26(52.0)$ & $2(4.0)$ & $3(2-3)$ \\
\hline $\begin{array}{l}\text { fractured existing denture } \\
\text { Performing relining }\end{array}$ & $18(36.0)$ & $24(48.0)$ & $8(16.0)$ & $0(0.0)$ & $2(1-2)$ \\
\hline Performing rebasing & $21(42.0)$ & $25(50.0)$ & $4(8.0)$ & $0(0.0)$ & $2(1-2)$ \\
\hline
\end{tabular}

\section{Discussion}

This questionnaire study was undertaken to assess the confidence level of dental interns when performing removable prosthodontic treatment. $100 \%$ response rate was achieved in this study as repeated reminders were sent to individual interns through emails, intern's private Viber group through the class representative and in person. In addition, the survey was completely online based with no additional requirement of printing and returning in person and was easily accessible through a link in the email.
Overall, majority of the interns were confident in performing RPDP and RCDP which resonates with previous studies. ${ }^{10,12-4}$ Some of them $(n=7)$ were confident in RPDP but lacked confidence in RCDP. This is understandable considering the technically demanding clinical procedures related to complete dentures relative to partial dentures. Conversely, there were also interns $(n=8)$ who lacked confidence in RPDP but were confident with RCDP. The questionnaires of these individuals were probed further to trace the reasons. Seven of them lacked confidence in 
repairing partial dentures; five of them lacked confidence in jaw relation, try-in and insertion in addition to clinical experience $(1.63 \pm 1.06)$ which was below the class average.

When the confidence levels were compared between genders, higher percentage of males were found confident compared to females in both the procedures. Previous evidences suggest a similar trend where males have been found to be relatively confident despite having received similar clinical teachings. ${ }^{4,15,16}$ However, statistically significant differences were only found for RCDP-related treatments. This is in contrast to a recent study where statistically significant sex difference was found for RPDP related procedures only. ${ }^{14}$

In the study, no statistical significant was observed when the level of confidence was compared with clinical experience. Both groups of interns felt confident regardless of the number of cases completed i.e. more than two or upto two prostheses. Though two prostheses seem adequate in our study it is difficult to define precisely the number of prostheses representing sufficient experience.

Contrastingly, there was another similar study where clinical experience had positive influence on confidence. ${ }^{17}$ However, these two studies cannot be compared directly since they assessed confidence level between three academic years without any consideration for the number of cases completed unlike our study. Nevertheless, an individual is expected to be more confident in procedures they perform more frequently than in procedures less frequently performed..$^{11,18,19}$

When looking at specific procedures related to removable partial and complete denture prosthesis, the interns were confident in most of the procedures except few, namely jaw relation, RPDP repair and RCDP relining and rebasing. Lack of confidence among the interns during jaw relationship or bite registration in both the removable prosthesis may have resulted from the subjective nature of the procedure, particularly in RCDPs. ${ }^{20,21}$ In addition, jaw relation recording in RCDPs is also patient dependent. ${ }^{22,23,24,25}$ The duration of edentulism and the age of the patient seeking treatment are few variables which may have affected individual experience and likewise, the ratings. This is clearly reflected by $42 \%$ of the interns who has also rated it "confident" with none recording "not confident".

In terms of RPDPs, most of the undergraduates in our institute are involved with tooth supported prosthesis which generally does not require carrying out jaw relationships or a bite registration and a simple maximum intercuspal relation at times can suffice the requirements. ${ }^{26}$ So, the interns' lack of experience with more extensive cases may have resulted in lower confidence.

It is not surprising that an overwhelming majority of the respondents in our study lacked confidence, rated either "not or low confidence" with respect to repairing RPDPs and in particular, while performing relining and rebasing for RCDPs. The lack of exposure to these procedures in the institute may have been the major reason. As observed, most of the patients seeking for these procedures alternatively opt for new dentures eventually, owing to the low cost of re-fabrication of these prostheses in the institute and the prospect of free prosthesis fabrication when fabricated by students for academic reasons. The remaining few are handled by postgraduate residents.

Overall, the objectives of the study were met, but it does have some limitations. We assessed the level of confidence which at times is overestimated by individuals than their competence. ${ }^{9,10}$ However, both competence and confidence are prerequisite for practice. $^{4}$ Secondly, the number of participants was low as the study included a single batch of interns from 
a single institute and single university which is difficult to generalize. So, the result has to be interpreted with caution.

\section{Conclusion}

Despite the limitations, the objective of analyzing the confidence levels of interns while undertaking removable prosthodontics was achieved. On the basis of findings of this study following conclusions can be made:

1. Overall confidence level of the interns at People's Dental College and Hospital while performing removable prosthodontics was satisfactory.

2. Male students exhibited a better overall level of confidence than female students. However, they were significantly more confident in performing complete denture prostheses only. Education providers need to be aware of this potential gender differences in self-perceived confidence levels and need for assistance.

3. The confidence level did not vary significantly with clinical experience.

4. The interns were confident in performing most of the procedures related to complete denture prostheses except jaw relation recording, relining and rebasing. Similarly, they lacked confidence while recording the jaw relationships/ bite registration and repair only with respect to the procedures of partial denture. Given an apparent lack of confidence in these procedures, special attention on these aspects may facilitate the interns to be more confident about themselves and their work and can improve overall patient care practices.

We hope our study will encourage such research in other dental institutions which will help monitor and improve dental education.

\section{Acknowledgments}

We would like to acknowledge the enthusiastic participation of all the graduating interns form the $16^{\text {th }}$ batch and thank them for their honest feedback. We acknowledge the help rendered by Sajani Manandhar for her contribution on biostatistics and all the faculties at the Department of Prosthodontics and Maxillofacial Prosthetics, People's Dental College and Hospital for their valuable suggestions in revising the questionnaire.

\section{References}

1. The Glossary of Prosthodontic Terms: Ninth Edition. J Prosthet Dent. 2017 May;117(5S):e1-e105. doi: 10.1016/j. prosdent.2016.12.001. PMID: 28418832.

2. Zitzmann NU, Hagmann E, Weiger R. What is the prevalence of various types of prosthetic dental restorations in Europe? Clin Oral Implants Res 2007;18(suppl 3):20-33.

3. Honey J, Lynch CD, Burke FM, Gilmour AS. Ready for practice? A study of confidence levels of final year dental students at Cardiff University and University College Cork. Eur J Dent Educ. 2011 May;15(2):98-103. doi: 10.1111/j.16000579.2010.00646.x. Epub 2011 Jan 31. PMID: 21492345.

4. Gilmour AS, Welply A, Cowpe JG, Bullock $\mathrm{AD}$, Jones RJ. The undergraduate preparation of dentists: Confidence levels of final year dental students at the School of Dentistry in Cardiff. Br Dent J. 2016 Sep 23;221(6):349-54. doi: 10.1038/sj.bdj.2016.686. PMID: 27659639.

5. Burton N. Heaven and Hell: The Psychology of the Emotions. USA: Acheron Press; 2015.

6. Packer M, Scott B, Davis D. An assessment of the influence of clinical demonstrations on the confidence of undergraduate dental students, when treating patients requiring removable partial dentures. Eur J Dent Educ. 1999;3(3):133-139.

7. Davey J, Bryant S, Dummer P. The confidence of undergraduate dental students when performing root canal treatment and their perception of the quality of endodontic education. Eur J Dent Educ.2015;19(4):229-234.

8. Herring HW Jr, Stephens AP. A survey of the removable prosthodontic clinical experience 
of dental students. J Prosthet Dent. 1982 Aug;48(2):198-201. doi: 10.1016/00223913(82)90112-3. PMID: 7050364.

9. Honey J, Lynch CD, Burke FM, Gilmour AS. Ready for practice? A study of confidence levels of final year dental students at Cardiff University and University College Cork. Eur J Dent Educ. 2011 May;15(2):98-103. doi: 10.1111/j.16000579.2010.00646.x. Epub 2011 Jan 31. PMID: 21492345 .

10. Shetty VB, Shirahatti RV, Pawar P. Students' perceptions of their education on graduation from a dental school in India. J Dent Educ. 2012 Nov;76(11):1520-6. PMID: 23144488.

11. Whitney EM, Walton JN, Aleksejuniene J, Schönwetter DJ. Graduating dental students' views of competency statements: importance, confidence, and time trends from 2008 to 2012. J Dent Educ. 2015 Mar;79(3):322-30. PMID: 25729026.

12. Coates AJ, Moore KR, Richards LC. Removable prosthodontics: a survey of practices and attitudes among South Australian dentists. Aust Dent J. 1996 Jun;41(3):151-8. doi: 10.1111/ j.1834-7819.1996.tb04846.x. PMID: 8768636

13. Punya Sekhri, Meera Sandhu, Vinod Sachdev. Perceived Competency towards Dental Practice among Interns of Various Dental Colleges in Delhi NCR, Global Journal of Medical Research 2015 15(2):25-30.

14. Sampaio-Fernandes M, Dutra M, Oliveira SJ, Reis-Campos JC, Azevedo Á, Figueiral MH. Students' self-confidence and perceived quality of prosthodontics education: A study in the Faculty of Dental Medicine of the University of Porto. Eur J Dent Educ. 2020 Aug;24(3):559571. doi: 10.1111/eje.12537. Epub 2020 May 27. PMID: 32362065.

15. Bartlett DW, Coward PY, Wilson R, Goodsman $\mathrm{D}$, Darby J. Vocational training: experiences and perceptions of vocational training reported by the 1999 cohort of vocational dental practitioners and their trainers in England and Wales. Br Dent J 2001: 191: 265-270.

16. Arena G, Kruger E, Holley D, Millar S, Tennant M. Western Australian dental graduates perception of preparedness to practice: a five year follow up. J Dent Educ 2007: 71:12171222.
17. Puryer J, Woods K, Terry J, Sandy J, Ireland AJ. The confidence of undergraduate dental students when carrying out prosthodontic treatment and their perception of the quality of prosthodontic education. Eur J Dent Educ. 2018 Feb;22(1):e142-e148. doi: 10.1111/eje.12271. Epub 2017 May 11. PMID: 28493628.

18. Choudhry N K, Fletcher R H, Soumerai S B. Systematic review: The relationship between clinical experience and quality of health care. Ann Int Med 2005; 142: 260-273.

19. Ericsson KA. Deliberate practice and the acquisition and maintenance of expert performance in medicine and related domains. Acad Med 2004; 79: S70-S81.

20. Nagpal A, Parkash H, Bhargava A, Chittaranjan B. Reliability of different facial measurements for determination of vertical dimension of occlusion in edentulous using accepted facial dimensions recorded from dentulous subjects. Journal of Indian Prosthodontic Society. 2014 Sep;14(3):233-242. DOI: 10.1007/s13191-0130315-1.

21. Sharry JJ: Complete Denture Prosthodontics, $3^{\text {rd }}$ ed. New York, McGraw-Hill, 1974.

22. Hughes GA. Discussion of "factors influencing centric relation records in edentulous mouths." J Prosthet Dent 1964 Nov-Dec;14(6):1066-68. doi.org/10.1016/0022- 3913(64)90174-X

23. Yurkstas AA, Kapur KK. Factors influencing centric relation records in edentulous mouths. 1964. J Prosthet Dent. 2005 Apr;93(4):305-10. doi: 10.1016/j.prosdent.2004.10.026. PMID: 15798677.

24. Kar SK, Tripathi A, Rai P. Reproducibility and Variability of Centric Relation Point in Completely Edentulous Patients 202. Journal of the California Dental Association 48(5):275280

25. Thompson JR. Concepts regarding function of the stomatognathic system. J Am Dent Assoc 1954;48:626

26. Carr, Alan B., David T. Brown, and William L. McCracken. McCracken's Removable Partial Prosthodontics. $12^{\text {th }}$ ed. St. Louis, Mo: Elsevier Mosby, 2011. 